\title{
An Analysis of Arabic-English Translation: Problems and Prospects
}

Md. Faruquzzaman Akan*, Md. Rezaul Karim, Abdullah Mohammad Kabir Chowdhury

Faculty of English, King Khalid University, Abha, Saudi Arabia

Corresponding Author: Md. Faruquzzaman Akan, E-mail: f.akan@yahoo.com

\section{ARTICLE INFO}

Article history

Received: September 11, 2018

Accepted: November 27, 2018

Published: February 28, 2019

Volume: 10 Issue: 1

Advance access: January 2019

Conflicts of interest: None

Funding: None

Key words:

Translation,

Meaning,

Text,

Source Language,

Target Language,

Equivalence,

Culture,

Usage

\begin{abstract}
This research paper is designed with a view to looking into various problems of translating Arabic texts into English and fixing them with prospective and suitable solutions. As translation is a very sensitive and subtle task of language studies, it involves some serious issues to deal with. However, it becomes a more complex task when we translate from Arabic to English. So, a translator must have the critical linguistic knowledge in tackling both the surface and underlying relations of language. Translation also entails the transferring and transforming a variety of characteristic elements from one language into the other. As Arabic and English are of different and distant origins, any translation from one script into the other poses a lot of difficulties such as in the areas of vocabulary, grammar, sound, style and usage. The present paper addresses the problems relating to translating the Arabic texts, specially of the language, into English as well as resolving the obstructions in a practical, possible and acceptable way on the bases of types of readership, text, context, culture and so forth. To make this work more accessible to the nonnative users of the Arabic language, Arabic IPA transcriptions are furnished wherever necessary.
\end{abstract}

\section{INTRODUCTION}

Translation is indispensable in our everyday life for its being a most diverse means of human communication. In these days of globalization and widespread immigration, the need of translation is increasing due to the continuous expansion of trade, science, culture, technology and so on. Translation is a field of contrastive linguistics since it is associated with at least two languages and their cultures. It is the process of conveying the message by transferring from one system of language to the other. That is to say, it is the technique used to transfer and/or transform the meaning of a written term or text of the source language into the target language using words which have direct equivalence, new words or terms, foreign words written in target language or using foreign words to fit the target language pronunciation. Bassnett, S. (1980:21) says, "Translation involves the transfer of 'meaning' contained in one set of language signs into another set of language signs through competent use of the dictionary and grammar; the process involves a whole set of extra-linguistic criteria also". A translation should be read by readers in its new language with the same enthusiasm and understanding as it was in the old. It should have the same virtues as the original, and inspire the same responses in its readers. So, a translator is both a reader and writer at the same time. Once in an answer to the question "What is a Translation?" Francis Steele gives a wonderful definition, "A translation should convey as much of the original text in as few words as possible, yet preserve the original atmosphere and emphasis. The translator should strive for the nearest approximation in words, concepts, and cadence. He should scrupulously avoid adding words or ideas not demanded by the text. His job is not to expand or to explain, but to translate and preserve the spirit and force of the original... Not just ideas, but words are important; so also is the emphasis indicated by word order in the sentence". Thus, translation from Arabic into English needs the processes and techniques which are used to transfer the meaning of the source language (i.e. Arabic) into the target language (i.e. English). This paper approaches translation activity from both academic and professional points of view.

\section{DISCUSSION}

Translation is an act of interlingual interaction which engages the cultural, religious, political etc components of language. 
In translation, we do not translate a word, sound, style or grammar but meaning. Meaning can be defined as a knotty arrangement or a product of different linguistic elements such as vocabulary, grammar, style, phonology and usage. Usually, anything which is not relevant to meaning is not considered as translation but at times, we may have some exception where sounds are more important than meanings for example, poetry. Meaning can be made out from a single word or a group of words so that something can be understood independently. Hence, a word is the smallest and a sentence is the largest unit of meaning. Translation needs to be viewed as an act of communication governed by consideration of comprehensibility and readability, rather than an act of prescription informed by dogmatic and obsolete views about correctness. So, translation is the exchange of the meaning of a source-language text by means of an equivalent target-language text.

English is the most common lingua franca for universal communication with 379 millions as native and at least 700 millions as foreign language users (Ethnologue, 22 $2^{\text {nd }}$ Edn./2019) all over the world. The need and demand of English has become greater for globalization, trade, commerce, information technology, immigration and so forth. English is one of the modern Aryan or Indo European languages but Arabic is one of the oldest Afro Asiatic languages of the world. Arabic is also one of the famous international languages having mother tongue of 319 millions (Ethnologue, $\left.22^{\text {nd }} \mathrm{Edn} . / 2019\right)$ Arab nationals who have some controls over the majority of the world nations economically, religiously and linguistically. The abundance of minerals has indebted many nations economically on the one hand and their language, Arabic being the language of the holy Quran helped them on the other hand to create world brotherhood. The Arab navigators, travellers and specially the Sufis and their spreading of Islam to the different non-Muslim world-nations helped them to come in contact of many.

Translation has been used by humans for centuries, beginning after the appearance of written literature. Modern-day translators use sophisticated tools and technologies to accomplish their work, and rely heavily on software applications to simplify and streamline their tasks. However, problems of translation are mainly caused by syntax (grammar), lexis or vocabulary (word), stylistics (style), phonology (sound) and usage of the source language (SL) which is Arabic and its translation into the target language (TL) being English in our current study.

\section{TRANSLATION METHODS}

The method of translation refers to the way we use to transfer the meaning from the source language into the target language. The main and major classification of methods of translation could be: (i) Manual and (ii) Mechanical, or (a) Literal and (b) Free. However, in Newmark's words, (1988:45), we translate either literally or freely. e.g.

\section{Literal Translation}

Literal translation involves the conveyance of denotative meaning of words, phrases and sentences in a text from one language to another. Therefore, literal translation works where there is a correspondence between the two languages in terms of semantics and structure. The literal translation is a bad practice, specially between the languages of distant sources like Arabic and English. Notably, literal translation often falters, particularly in the case of multi-word units like collocations and idioms. But literal translation may sometimes work in the case of multi-word units which can be illustrated as 'الحرب و السلام' /alharb wa assalam/- 'war and peace'.

This method could be applied in three different ways: Word-for-Word Translation, One-to-One Literal Translation and Literal Translation of Meaning. The ancient Greeks translated texts into Latin using the literal Word for Word Translation method. Also, one to one basis of literal substitution was preferred. Here, fluency for target readers is more important than fidelity.

a) Word-for-Word Translation: A word-for-word translation is the way of transferring meaning of each and every word of the source language into the target language with its equivalent words. This means to translate individual words. It is a bit risky method since it may upset meaning. So, it is not recognized as a mature translation practice because it does not take structural mismatches such as differences in word order, modification etc between languages into consideration. It thoroughly ignores the target language and the context. Here, each and every word or item is translated into TL with an equivalent and similar meaning. e.g.

Arabic: ذهب نجين إلى جدة || ذهahaba nadzin ila dziddah ||

English:? Went Najin to Jeddah.

Here, the correct word order for the translation in English should be 'Najin went to Jeddah'. In Arabic verbal sentences, the verb comes first but in English sentences, the verb comes after a noun or noun equivalent in a sentence. So, the above English word-for-word translation is faulty.

b) One-to-One Literal Translation: It is a broader form of translation. In this method, we consider the collocation meanings and translate each SL word or phrase into an identical word or phrase in the TL with the same number, grammatical class and type of language. That is, a noun is translated into a noun, an adjective into an adjective and so on and so forth. In the same way, an idiom should be translated into an idiom, a collocation into a collocation, a proverb into a proverb, a metaphor into a metaphor etc. The following example shows the translation of an Arabic idiom into English. e.g.

Arabic: 'طويل لسان'/tawil lisan/

English: 'long tongue' (i.e. abussive)

c) Literal Translation of Meaning: It is the translation of meaning as closely, accurately and completely as possible. This is why sometimes it is called Close, or Direct Translation. It takes into account for the TL grammar and word order. Metaphorical and special uses of language are also accounted for in the TL. This method conveys different meanings in different texts, contexts and combination with other words. This method can be most acceptable among literal translations. e.g. 


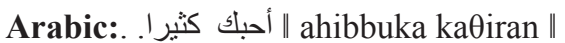

English: I love you a lot.

\section{Free Translation}

It is the act of rendering the wording, structure, and grammar of a source document into the translation as closely as possible. Here, fluency is not as important as fidelity. This is often made for students and scholars who have knowledge of the language they are reading. This method is considered to be better than the previous one, the literal translation. Free method means to translate without any constraints. A free translation is a translation that reproduces the general meaning of the original text. It may or may not closely follow the form or organization of the original. It is associated with translating the spirit, or the message, not the letter or the form of the text. It does not translate each and every single word in a text. The translator can translate the way s/he understands. It is convenient both for the translator and the person who reads it. As for free translation, it is another translation method whereby an SL literary text is relayed into a TL by reproducing the matter without the manner, or the content without the form. So, it is usually a paraphrase that is much longer than the original and over and over again wordy and pretentious. e.g.

Arabic: ليلى امر أة شابة وطيبة القلب.

|| laila aimrah Jabat wa taibatu alqalb \|

English: .Laila is a young and kind-hearted woman.

Arabic: لقد سبق أن أخبرتك الا تستخدم قلمي.

\| laqad sabaq an ak $^{\mathrm{h}}$ bartuka alla tastak ${ }^{\mathrm{h}}$ adim qalami \|

English: I had already told you not to use my pen.

The common methods of free translation could be classified as Adaptive Translation, Semantic Translation, Idiomatic Translation, Communicative Translation, Pragmatic Translation, Faithful Translation, Creative Translation, Cognitive Translation, Information Translation, Stylistic Translation, Scientific Translation etc.

\section{RESEARCH FINDINGS}

A translation problem is any difficulties we come across at translating that invites us to stop translating in order to check, recheck, reconsider, rethink or rewrite it or use a dictionary, or a reference of some kind to help us overcome it and make sense of it. Translation problems can be posed essentially by the grammar, word, style, sound and/or usage of the concerning languages. Here, some problems like syntactic, semantic, stylistic, phonological and usage are discussed in detail:

A. Syntactic Problems: There are some problems related to the syntax/structure of the two languages (i.e. Arabic and English) because they belong to two different and distant language families and for other reasons. Syntactic asymmetries between Arabic and English require special attention from translators. Most importantly, the translator needs to be aware of the mismatches at the sentence level which involve word order variation. e.g.

Verb 'Do': 'Do' as the main verbs in English are equal to 'يفعل'/jafal/in Arabic. The verb 'Do' (Present) and 'Did'
(Past) with 'يفعل' for Arabic negative (and at times affirmative) sentences indicate the tenses only. The verbs 'Do' and 'Did' in questions have the Arabic equivalent as 'هل' هل "

Arabic: هل تحب الزهور؟ hal tuhib azzuhur ||

English: Do you like flowers?

Verb 'Have': The verb 'Have' to show ownership (i.e. 'يملك/jamlik/in Arabic) has fewer problems as the main verb (though it has no use as an auxiliary verb) in Arabic.

Questions: In Arabic, for Yes/No-questions 'هل' can be used in both present and past tenses but for Wh-questions,

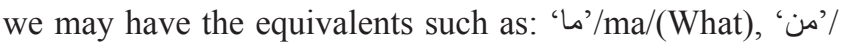

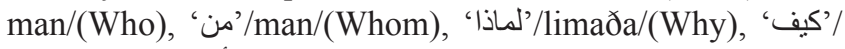

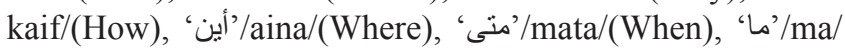
(Which), 'لمن'/liman/(Whose) etc. e.g.

Arabic: : المن اين عاي؟ min aina ali ||

English: Where is Ali from?

Negations: The Arabic words like 'لy'/la/, 'ما'/ma/, 'لم'/ lam/, 'لن/lan/etc have equivalents in English as 'no', 'not' etc. e.g.

Arabic: لا لا لم أعرف la la arif \| (Present) vs || (Past)

English: I do not know. (Present) vs. I did not know. (Past)

Word Orders: Two languages have different orders of words. For English, it is as Subject + Verb + Object/Complement, but in Arabic, we have the following two structures:

a. Nominal: Subject + (Verb) + Object/Complement:nadzin (S) mudarris (C) ||

b. Verbal: Verb + Subject + Object/Complement: | ðahaba (V) ali (S) ila assuq (C) || ذهب علي إلى السوق

Usually, English has only nominal sentence structures (i.e. SVC). Arabic is syntactically more flexible than English. In Arabic, there are generally three accepted word orders: VSC, SVC and VCS. But a typical Arabic structure of a sentence is as VSC: the 'verb' followed by a 'subject' which is further followed by an 'object' or 'complement' but in English, it is as SVC: the 'subject' followed by a 'verb' which is further followed by an 'object' or 'complement'. But with some change of meaning, the English word order could be different too.

Personal Pronouns: Personal pronouns can be omitted (or, embedded) in verbal Arabic sentences if not to put emphasis. e.g.

Arabic: أنا) اشتريت سيارة) || (ana) iftaraitu saiarah ||

English: I bought a car.

Adjectives: English attributive adjectives usually come before nouns but in Arabic, the opposite is commonly found. e.g.

/ سيارة حمر اء/saiarah hamra/vs. (a) red car

Tenses: Arabic and English have two major types of tenses (e.g. present and past). Arabic has no progressive and perfective form of tenses. In Arabic, the present and past perfect tenses are treated as past simple. The present progressive is treated in Arabic as present simple but to indicate time 'الان/alan/is used and similarly, the past progressive is used as past simple. The present and past perfect progressive tenses are not found in Arabic. 
Conditional Sentences: Arabic has two types of conditional sentences. But English has three. The translation of future in the past creates the main problem in Arabic.

Articles: Like English, there is no indefinite article in Arabic. It has only definite articles (i.e. 'ال/al/al/- 'the').

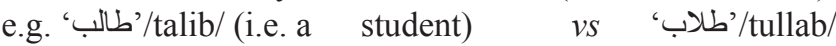

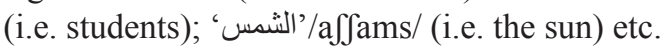

Genders and Numbers: English does not have any grammatical genders whereas Arabic has. e.g. 'معلم'/muallim/ (i.e. a male teacher) vs. 'معلمة/muallimah/(i.e. a female teacher). Also, English has two types of numbers. e.g. Singular (i.e. a teacher) vs. Plural (i.e. teachers), but Arabic has three types of numbers. e.g. Singular: 'معلم'/muallim/ (i.e. a teacher), Dual: 'معلمان'/mualliman/(i.e. two teachers) and Plural: 'معلمون'/muallimun/ (i.e. teachers)

B. Semantic Problems: As words, the basic units of translation play a very significant role, students or translators face more problems here. These problems take place when a word, phrase or term cannot be understood directly and clearly; misunderstood or not found in the standard lexicons/dictionaries. The other major semantic or lexical problems encountered by translators and students are as follow:

Equivalence: In the whole process of translation, equivalence is the key concept for any languages. The notion of equivalence is introduced as a major parameter of human communication. It should be noted that the notion of equivalence relates to the ordinary sense of the verb that we translate. That is why we are often asked to translate our feelings into words and our words into actions etc. In general, we can speak of types of equivalence such as formal, functional and ideational. Firstly, 'formal' equivalence seeks to capture the form of the SL expression. Here, form relates to the image employed in the SL expression as can be illustrated by the underlined Arabic idiomatic expression and its underlined formal English equivalent. e.g.

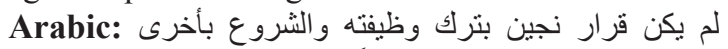
حكيماً كالقافز من الر مضاء إلى النى النار

\| lam jakun qarra nadzin bitark waðaifatah wa a frua biukhra hakim - kalkafiz min arramada: ila annar ॥

English: Najin's decision to leave his job for a new one was ill-thought- out of the frying pan into the fire.

Secondly, we have 'functional' equivalence which seeks to capture the function of the SL expression independently of the image utilized by translating it into the TL expression that performs the same function:

لم يكن قرار نجين بترك وظيفته والثروع بأخرى حكيماً كالمستجير من الرمضاء بالنار

\| lam jakun qarra nadzin bitark waðaifatah wa ajrua biukhra hakim- kalumustadzir min arramada: binnar \|

English: Najin's decision to leave his job for a new one was ill-thought- from hot to hotter.

Sometimes, 'formal' and 'functional' equivalence may coincide to furnish what could be called 'optimal' translatability. The following Arabic proverb and its English translation illustrate this:

Arabic: إن الطيور على أشكالها تقع. inna alttur ala aJkaliha taqui II

English: Birds of a feather flock together.
Finally, there is 'ideational' equivalence which aims to convey the communicative sense of the SL expression independently of function and form. The English translation of the Arabic example involving 'من الر مضداء إلى النار' reflects this type of equivalence:

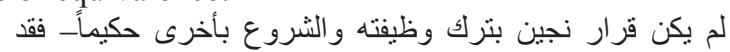
سارت الأمور من سيء إلى أسوء

|| lam jakun qarra nadzin bitark waðaifatah wa a frua biukhra hakim- faqad sarat alaumour min sia: ila aswa \|

English: Najin's decision to leave his job for a new one was ill-thought - things went from bad to worse.

Monosomy: A word which has only one meaning is termed monosemous. Monosemous words and terms cause no serious problems because they are standardized and available in the TL with one single meaning.

Polysemy: A word which has more than one meaning is described as polysemous. e.g. 'طويل'/tawil/ (i.e. tall) and 'طويل'tawil/ (i.e. long). Problems of translation arise when a polysemous word is mistaken for a monosemous one, where one meaning is wrongly assigned to it in all texts and contexts.

Synonymy: Words which have the same meaning or similar meaning are called synonyms. Synonyms pose the problems concerning the difference between the levels of closeness or absolute identification of the meanings of synonymous words compared with one another in the same language as well as between the two languages, the SL and the TL, and how effective/ineffective that difference may be on meaning in a context.

Collocations: Two or more words which usually occur together consistently in different texts and contexts are called a collocation. We can say, it is the habitual co-occurrence of words. e.g. 'شاهي ثقيل'/Sahi Oaqil/ (i.e. strong tea)

Idioms: Types of phrases which have fixed forms and special meanings that cannot be made out from the direct meaning of their words are called an idiom. e.g. 'ذو وجهبن/ 'ذو wadghin/- a hypocrite

Proverbs/Sayings: Proverbs are popular fixed sayings which are part of culture. Therefore, they have their own problems of translation for everybody, specially students of translation. Here, we have the Arabic proverbs and its English translation illustrated below:

Arabic: الصدق منجاة. alsidq mindzah ||

English: Honesty is the best policy.

Metaphors: Metaphors are an indirect, non-literal language. They are used to say something but mean something else. They are usually quite problematic and difficult. A metaphorical translation involves the translation of SL metaphors into TL metaphors. In creative metaphors, the vehicle (i.e. the form) and the tenor (i.e. the content) become intertwined and subsequently inseparable. However, metaphors are not always creative; they are frequently used as decorative.

Morphology: Morphology deals with the forms of words. It corresponds to that branch of Arabic linguistics known as 'علم الصرف'/ilm assarf/. In the case of Arabic-English translation, the problem stems from the fact that 
Arabic morphological system is more flexible than English morphological system is. Derivation is a core aspect of morphology. It allows the derivation of numerous words forms, with different shades of signification, from the same root.

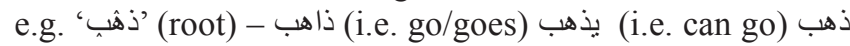
(i.e. went) But English morphological system is not so rigid with respect to all parts of speech. e.g. big - bigger - the biggest. Morphological differences between languages tend to pose a serious problem in the case of Arabic-English translation.

Connotations: A connotation has the meaning that a word can be suggested in addition to its denotative meaning. For instance, the Arabic word ' 1 'اد'/asad/ (i.e. a lion) can signify in addition to its known meaning as 'a strong and brave person'. Words acquire their connotation from the culture to which they belong, as in every culture, people associate particular signification with particular words till they become the shades of those word meanings.

Paraphrases: It is a brief explanation used when there is no way to make an unclear term or expression (e.g. cultural or religious etc) understandable. The Arabic word 'ردة/riddah/without explanation will not be clear to the English speakers though meaning 'to refrain from' but not having the exact meaning. So, a paraphrase is usually longer than the original.

Naturalization: It is a translation strategy where SL usage is converted into normal TL usage. This process is basically carried out at lexical, collocation and structural levels. By way of illustration, the Arabic lexical item 'قابل للتفاوض' qabil littafaud/ is translated as 'negotiable', the Arabic collocation 'يعير الانتباه'/jauir ulintibah/ is translated into 'to

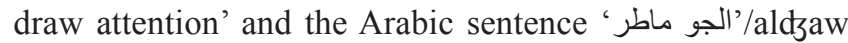
matir/translates into 'It is raining now' in English. In that case, naturalization of usage is inevitable in translation, as literal translation would produce unnatural expressions in the TL in cases where naturalization is called for.

Moreover, parallelism, literal translation, phrasal verbs, localization etc also create problems in translating a term or text.

C. Stylistic Problems: In recent times, style is considered to be an essential part of meaning. It may cause problems for translators. It includes various types of figure of speech. Among the stylistic problems, there will be the following points to consider:

Fronting: A word, a phrase or a clause can be put in the beginning of a sentence in a usual way. Such fronting is done on purpose to achieve a stylistic function of some kind: emphasis of the fronted word, or drawing attention to its special

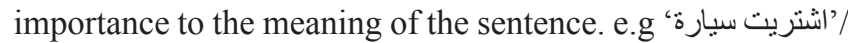
iftaraitu saiarah/ instead of 'سيارة اشتريت'/saiaratu iftaraitu/. Translators may be unfamiliar with such a stylistic function, and, hence ignore the style of fronting. But this is not advisable since meaning will be affected, however indirectly. It creates fewer problems in Arabic than in English.

Clichés: There are some expressions that have some kind of comparison. e.g. The Arabic expression 'مشغول مثل النحل'/mafyul mi $\theta$ la alnahal/ may be translated as 'very busy' in English.

Parallelism: Two clauses or sentences may have the same structure and are, therefore, parallel. Such style of parallelism is not always easy to translate, and may have its problems in both Arabic and English.

Short vs. Long Sentences: To combine short sentences into one or to divide long sentences into short ones may cause confusion.

Redundancy: The employment of extra and unnecessary words expressing something might have some purpose in translation. So, it should not be dropped but taken care of.

Nominalization vs. Verbalization: Unlike English, Arabic has two types of sentence structures namely noun dominated and verb dominated. This is an important area of Arabic to English translation.

Irony: It is a very difficult style of any languages. Here, the translator has to be very careful. It is of three types: verbal, situational and dramatic irony

Anaphora: An anaphora is a literary technique where several phrases or verses begin with the same word or words.

Passive vs. Active Style: There are some differences between the Arabic passive and the English passive and its implications on translation. The Arabic passive is predominantly emotive although it can be used for other purposes such as thematization for emphasis. The English passive is also emotive albeit to the lesser extent. Like the Arabic passive, it is also used for the purpose of thematization. Let us examine the following examples:

Arabic: قتل علي بواسطة مؤيد. qutila ali biwasitat muaid \|

English: Ali was killed by Muaid.

The misleading error in this translation is that while the SL text explicitly says 'Muaid' is the real perpetrator, the TL text implicitly portrays 'Muaid' as a sheer accomplice. The TL suggests that 'Muaid' did not kill 'Ali' by himself but made somebody else to kill him (i.e. Ali). The translation of

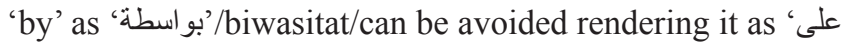
'يد/ala jed/which confirms the real perpetrator of the action by the doer. e.g. 'قتل على يد مؤيد.' || qutila ala jed muaid || Again, we have the following example,

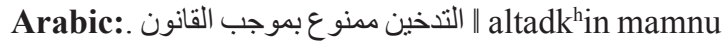
bimudzab alqanun ॥

English: Smoking is forbidden by law.

It is to be noted that the translation of 'by' as 'بو اسطة' can be maintained as a second option in cases where the action is physically done through the agent.

Of course, besides these there are other issues in translation like ambiguity, (in)formality, punctuation, repetition and variation, simple vs. complex style, euphemism etc.

D. Phonological Problems: Phonological problems or issues are those which are connected to sounds and their effects on meaning. These characteristics and effects may sometimes be very important for meaning and text as a whole where sounds are more significant than senses. Phonological features become an important aspect of translation when form comes to the fore in discourse and presents itself as inseparable from content. This is where phonological features emerge as part and parcel of content that need to be taken care of by the translator. The clearest manifestation of phonological features occurs in poetry (e.g. alliteration, rhyme, meter, paralleled repetition, etc.) where defamiliarization and the creation of 
new paradigms are embodied in such features (Fowler, 1996). Hence, translating verse into verse is the most challenging task in translation; it may require, as many believe, a poet translator in order to render the formal properties that improvise poetic features which legitimate the discourse in this genre. So, careful and repeated reading, specially poetry, dropping unnecessary words and looking for the widest possible range of synonyms for key words, rhyming words etc can help the translators. This is very necessary for rhythmical language. So, we have to consider the issues about Arabic-English translation. e.g. Sounds are important in language, specially when they combine together in different patterns to give meaning. To support the importance of sounds, we can quote Lawson's (1981:97), “... much more meaning is conveyed by rhythm and stress than we recognize". The sound effect could be more important than meaning and it plays an aesthetic function of language. So, we have the following points to talk about. e.g.

Tone: It is an attitude of a writer towards a subject or an audience. Tone is generally conveyed through the choice of words, or the viewpoint of a writer on a particular subject.

Rhyme: It is a type of matching sound found at the end of words in a verse.

Rhythm: It is a phonological feature of language consisting of a regular stressed and an unstressed syllable.

Alliteration: In English, it is an initial rhyme involving the repetition of the same consonant sound at the beginning but in Arabic, it is at the end of words.

Assonance: It is the repetition of the same vowel sound in the middle of words. It is not so clear in Arabic as in English.

Onomatopoeia: The use of imitative and naturally suggestive words for rhetorical, dramatical or poetic effect is termed onomatopoeia.

Other issues like consonance, meter, foot, beat, off beat etc are also important. So, we can say phonological features and effects have an important role in translation where sounds are more significant than senses.

E. Usage Problems: Usage subsumes various issues of language such as cultural, religious, social, geographical, political and so forth. Examples that may demonstrate approximation are so many items that may belong to various linguistic levels. These issues are great factors of translation. e.g.

Cultural Terms: Anthropologists suggest that language is culture bound. So, a culture-specific expression in the SL is translated into a cultural substitute in the TL. e.g. The expression for greeting in Arabic 'صباح الخير'/sabah alk ${ }^{\text {hir/ has }}$ the meaning in English as 'good morning' whereas 'صباح جياح' جيد' is not accepted culturally or socially in Arabic though it may have same meaning. Similarly, 'good evening' is not correct in English as a parting greeting at night.

Religious Terms: The Arabic lexical item 'الها' (Allah) is translated in English as 'God' with little change in meaning because the word 'اله' has no male/female and singular/plural distinction, specially in Arabic.

Political Terms: In Arabic, 'شهيد/Sahi:d/ is a person who died for the cause of religion or the state and its translation in English is 'martyr' which might be different from Arabic.
Possibility: The possibility of saying something in the TL or not, for example the Arabic term 'راتب ضخم'/ratib da$\mathrm{k}^{\mathrm{h}} \mathrm{im} /$ is translated in English as ' $\mathrm{a}$ fat/handsome salary'.

Logical Acceptability: The logical acceptability of an expression may be significant. e.g. The logical translation of 'يسحب كلامه/يعتذر 'ئرab kalamuhu, or jataðir/ is 'to eat one's words' but the Arabic term 'باكل كلماته'/jakul kalimatuh/ is not correct as nobody can eat words.

Frequency: The frequency or non-frequency of an expression or a grammatical structure matters a lot. e.g. The frequent translation of 'يزرع الثقاق'/jazra alfiqaq/ is 'to sow

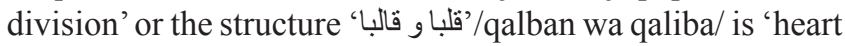
and soul'.

Familiarity: The degree of familiarity or strangeness of an expression, or a grammatical structure can cause confusion. e.g. The familiar translation of 'اسباب وجيهة'/asbab waziha/ is 'good reasons'.

Understandability: The understandability, or not of an Arabic expression such as the translation of 'مهمة شاقة 'م 'ماقة'/mahammah Jaqah/ is 'a difficult/hard/daunting task' in English.

\section{SUGGESTIONS FOR TRANSLATION PROBLEMS}

Any problems demand a solution. So, without a solution, there is no great or real use of pinpointing a translation problem. Indeed, without solutions to translation problems, we stop translating altogether. This is why all problems located in this work are accompanied by the same time with their possible solutions. In order to be acceptable, any suggested solutions are made clear, reasonable, feasible, reliable, applicable, contextual and in the right direction. Otherwise, it will not be acceptable. The solutions proposed to the translation problems are, therefore, based on the following criteria:

Untranslatability: The problems of translating from Arabic to English can be termed as untranslatability which as such can straightly be of four types: cultural, geographical, religious and linguistic. Problems of loss in translation include difficulties encountered by the translator when faced with terms or concepts in the SL that do not exist in TL.

Types of the Text: The text may be general, technical, religious, political etc. For example, books with humour require a translator with wit, and where there is an unusual or intricate use of language (in the case of dialects, slang terms, and even cadence), a good understanding of and ability to translate the spoken word is essential. Sometimes, the idiomatic or religious terms need a little explanation for English readers.

Genders: A decision may be made that a female translator is better for the text with a particularly feminine subject matter, or a male for one on a particularly masculine topic.

Major Linguistic Contexts: The whole text could be one sentence, one paragraph, a poem or a short story etc. Minor Linguistic Contexts: It is to take account of the preceding and following word, phrase, clause or sentence. Types of Relationship: The level of the reader as such uneducated, educated, highly educated, specialists, children, etc is of a great consideration for translation. 
Areas of Interest: Areas that could present some difficulty in translation could include extensive use of dialect, humour, poetry or literary conceit, all of which will need to be approached in a systematic and preagreed manner.

Areas of Specialty: Some books focus on specialist areas, perhaps involving historical facts or scientific theory, for instance. In this case, the translator should have a good working knowledge of the subject matter, or a proven ability to research, disseminate and extrapolate information successfully. In some cases, travelling to the host country may be necessary.

So, it should be kept in mind that one problem can have more than one solution, as much as one solution can be applied to solve more than one problem.

\section{CONCLUSION}

Translation is a very tricky task of linguistics. It has always been a complicated job, specially transferring the characteristics and properties of two languages belonging to different origins. Richards, I. A. (1953:13) remarks, "Translation probably is the most complex type of event yet produced in the evolution of the cosmos". So, translating Arabic texts into English necessitates a huge bilingual expertise. Moreover, the cultural and religious influences are very strong in both the languages. It has been shown that though lexical problems are greater in number, grammatical, stylistic, usage and phonological problems are not insignificant. For instance, Arabic has more inflexion than English. Translation programmes at the undergraduate and postgraduate levels have become a common feature of universities and academic institutes due to the increasing demand in the job market. Therefore, the charge of translation teaching is often assigned to bilingual academics specializing in literature and/or linguistics. Translation is not merely about conveying meaning, it is something more. Although to resolve the challenges of translating Arabic into English or finding any straightforward means is in no way an easy task, a comparative study will benefit the translators, readers, practitioners, learners and teachers in this field with a more clear-cut information.

\section{ABOUT THE AUTHORS}

Md. Faruquzzaman Akan, Md. Rezaul Karim and Abdullah Mohammad Kabir Chowdhury, three Bangladeshi nationals are presently working at King Khalid University, Saudi Arabia. They have been teaching English as a foreign and second language for a long time. Mr. Akan is also the author of a good number of research papers and academic textbooks in English. His major areas of interest are applied linguistics, ELT, contrastive linguistics, translation, phonetics, phonology, syntax etc.

\section{REFERENCES}

Akan, M.F. (2018). Transliteration and Translation from Bangla into English: A Problem Solving Approach. British Journal of English Linguistics, Vol.- 6, Issue- 6,
2018, pp. 1-21.

Akan, M.F. et al (2018). A Discourse on Bangla Translation of Arabic Texts: Problems and Proposals. International Journal of Language, Literature and Translation, Vol. 2, Issue- 4, 2018, pp. 1-21.

Akan, M. F. (2014). The Linguistic Overviews of Arabic and Bangla: A Comparative and Contrastive Analysis. Bangladesh Research Foundation Journal, Dhaka, Bangladesh, Vol. 3, No.1, April 2014, pp. 103-110.

Al-Hamdalla, R. (1998). Problems and Approaches to Translation with Special Reference to Arabic. Journal of King Saud University, Languages and Translation, 10, 23-38.

Al-Hassnawi, A. (2000). Aspects of Scientific Translation: English into Arabic Translation as a Case Study. www. TranslationDirectory.com.

Al-Masri, H. (2004). Semantics and Cultural Losses in the Translation of Literary Texts, unpublished $\mathrm{PhD}$ thesis: Purdue University.

As-Safi, A. B. (2011). "Translation Theories, Strategies and Basic Theoretical Issues", Petra University, Amman.

Awwad, M. (1989). Equivalence and Translatability of English and Arabic Idioms, Papers and Studies in Contrastive Linguistics, Vol. 26, pp. 57-67.

Bahameed, A. (2007). Hindrances in Arabic-English Intercultural Translation. Translation Journal. Retrieved from: http://ranslationjournal.net/journal/43culture.htm.

Baker, M. (1992). In Other Words: A Course book on Translation. London and New York: Routledge.

Baker, M. (1992). "In Other Words: A Course Book on Translation", London: Routledge.

DOI: 10.1515/cllt-2013-0018, June 2013.

Bassnett, S. (1980). Translation Studies. London and New York: Routledge.

Bell, R. (1991). Translation and Translating, (Longman, London and New York).

Catford, J. C. (1965). “A Linguistic Theory of Translation”, London: Oxford University Press. Walton Street, Oxford 0x2 6 D P Oxford, London.

Elyas, A. (1989). "Theories of Translation" University of Mowsil: Mowsil. Linguistics Across Culture, Ann Arbor: University of Machigan Press.

Farghal, M. (2012). Advanced Issues in Arabic-English Translation Studies. Kuwait: Kuwait University Press.

Frawley, William, ed. (1984). Translation: Literary, Linguistic, and Philosophical Perspectives. Newark, Delaware, University of Delaware Press, 218 p.

Ghazala, H. (2008). Translation as Problems and Solutions- A Textbook for University Students and Trainee Translators (Special Edition), Dar El- IlmLilmalayin Publishing Press.

Ghazala, H. (2007). "Simultaneous Development of SL and TL Skills in Translation Class", A Conference, Sultan Qaboos University, Oman.

Gadacha, A. (2006). On Translatability from English into Arabic: Words and Beyond. Meta: journal des traducteurs/Meta (Translators' Journal), 51, 1, 36-50.

Hatim, B. (2012). Teaching and Researching Translation. London: Longman.

Hatim, B. (1997a). Communication Across Cultures: Trans- 
lation Theory and Contrastive Text Linguistics. Exeter: University of Exeter Press.

Hatim, B. (1997b). The Translator as Communicator. London and New York: Routledge.

Hatim, B. and Mason, I. (1990). Discourse and the Translator. London and New York: Longman.

Huq, Daniul, M. (2008). The Dhaka University Journal of Linguistics: Vol. 1 No.2 August, 2008, Published on August 2009 (C) Registrar, Dhaka University, ISSN-20753098, pp. 45-66.

Lambert, W. E. (1978). "Psychological approaches to bilingualism, translation and interpretation", Language Interpretation and Communication, ed. by David Gerver and H. Wallace Sinaiko, pp. 131-143, New York, Plenum Press.

Levy, J. (2000). "Translation as a Decision Process" in Venute, L (ed.) The Translation Studies Reader. London: Routledge.

Neubert, A. and Gregory, M. S. (1992). Translation as Text. Kent: The Kent State University Press

Newmark, P. (1988). A Textbook of Translation. London: Prentice Hall.

Newmark, P. (1982). The Translation of Authoritative Statements META 27(4).

Newmark, P. (1981). Approaches to Translation. Pergamon Press: London.

Nida, E. A. (1997). The Nature of Dynamic Equivalence in Translating. BABEL 13: 99-103.

Nida, E. A. (1994). Translation: Possible and Impossible. turjuman 3(2): 147-163.

Nida, E. A. (1964). Toward a Science of Translating. Leiden, E. J. Brill, 331 p.

Paul, G. (2009). Translation in Practice, a symposium edited by Gill Paul. At British Centre for Literary Translation, Arts Council England, The Society of Authors, British Council, and Dalkey Archive Press.

Richards, I. A. (1953). Towards a theory of translation. "Studies in Chinese thought", American Anthropological Association. Vol. 55, University of Chicago Press.

Robbert, P. (1982). Linguistics and Translation, IRAL 20, No. 3.

Saedi, L. (1996). Translation Principles vs. Translator Strategies. META 4(3): 389-392.

Saraireh, M. (1990). Some Lexical and Semantic Problems in English-Arabic Translation. Madison: The University of Wisconsin. [Doctoral Dissertation]

Searle, J. R. (1981). Expression and Meaning. Cambridge: Cambridge University Press.

Shunnaq, A. (1993). "Lexical Incongruence in Arabic-English Translation due to Emotiveness in Arabic". In “Turjuman". Vol. 2, No. (2): pp. (37-63).

Shamaa, N. (1978). A Linguistic Analysis of Some Problems of Arabic to English Translation. Unpublished doctoral thesis, Oxford University.

Simpson, P. (2004). Stylistics: A Resource Book of Students, Routledge: London and New York.

Steiner, G. (1975). After Babel: Aspects of Language and Translation. London, OUP, 507 p.

Yaroslav, V. (2010). "On the Linguistic Definition of Translation". Journal of Siberian Federal University. Humanities \& Social Sciences- 2, pp. (33-81).

Wehr, H. \& Cowan, J. M. (1976). A Dictionary of Modern Written Arabic, (Third Edn), (Ithaca, New York: Spoken Language Services, Lnc.).

Wilss, W. (1982). The Science of Translation. Tubingen. Narr. 